\title{
Identification of Linear Climate Models from the CMIP3 Multimodel Ensemble
}

\author{
Steven R. Weller* Brenton P. Schulz* Brett M. Ninness * \\ * School of Electrical Engineering and Computer Science \\ University of Newcastle, Callaghan, NSW 2308, Australia \\ e-mail: steven.weller@newcastle.edu.au,brenton.schulz@uon.edu.au, \\ brett.ninness@newcastle.edu.au
}

\begin{abstract}
In this paper, we investigate an ensemble of atmosphere-ocean general circulation models (AOGCMs) participating in phase 3 of the Coupled Model Intercomparison Project (CMIP3), and whose dynamic behavior is emulated by the reduced-complexity climate model MAGICC6. Using a superimposed impulse in solar radiative forcing for the purposes of system identification, we identify 12 AOGCMs in the CMIP3 ensemble for which low-order linear, timeinvariant (LTI) models are able to very closely approximate MAGICC6 surface temperature projections under each of the four greenhouse gas (GHG) emission scenarios known as the Representative Concentration Pathways (RCPs) in the IPCC Fifth Assessment Report (AR5), even when extended to centennial timescales. The linear climate models identified in this paper are suitable for the analysis of feedback-based approaches to mitigation aimed at stabilizing global-mean surface temperature, and will inform future quantitative assessment of closed-loop approaches to geoengineering of the climate based on solar radiation management (SRM).
\end{abstract}

\section{INTRODUCTION}

In response to the risks associated with anthropogenic climate change, the international community has sought to implement binding emissions reductions treaties, of which the Kyoto protocol is the most prominent example. Such treaties are a form of mitigation: attempts to limit the accumulation of atmospheric carbon dioxide $\left(\mathrm{CO}_{2}\right)$ and other greenhouse gases (GHGs) by restricting anthropogenic emissions.

The limited effectiveness to date of the mitigation-based response to anthropogenic climate change has prompted a network of scientists, entrepreneurs and advocates to consider a "Plan B" response known as geoengineering or climate engineering. Broadly defined, geoengineering involves deliberate and large-scale interventions in the Earth's climatic system to counter impacts of climate change such as sea level rise, more severe weather extremes, and ocean acidification (Lenton and Vaughan [2009]).

Global-scale implementations of either mitigation or geoengineering implicitly involve feedback of the climate state in order to inform decision-making, in effect creating a closed-loop system with the global climate as the system being controlled, and with the influence of a policy-based response modeled as a feedback controller (Jarvis et al. [2012], MacMartin et al. [2013]).

Whether for mitigation or geoengineering, climate models play a key role in the formulation of control-based approaches to climate change responses. The aim of this paper is to develop a suite of low-order, linear time-invariant (LTI) climate models suitable for model-based feedback control design of both mitigation and geoengineering responses to climate change, and to serve as a resource for control researchers seeking simplified climate models for these purposes.

The research of Jarvis and colleagues (Jarvis et al. [2008], Jarvis et al. [2009], Jarvis et al. [2012]) laid the groundwork for feedback control-based interpretation of sequential, mitigation decision-making frameworks seeking to stabilize global-mean surface temperatures. In Jarvis et al. [2009], the assumed 20-year duration of an emissions treaty review period plays the role of the sampling period, and an optimal control strategy is devised so as to minimize the peak reduction rate of anthropogenic $\mathrm{CO}_{2}$ emissions whilst limiting warming to $2{ }^{\circ} \mathrm{C}$ above preindustrial levels, subject to model uncertainty. The $2{ }^{\circ} \mathrm{C}$ limit is an internationally accepted value broadly representing the maximum warming that can be tolerated without risking dangerous anthropogenic interference in the climate.

In recent research, MacMartin et al. [2013] have proposed a feedback control-based approach to a class of geoengineering responses known as solar radiation management (SRM). In SRM, a planetary cooling effect is created by reflecting a fraction of the incident solar radiation before it can cause warming, e.g. by injection of reflective stratospheric sulphate aerosols, or cloud reflectivity enhancement through the addition of condensation nuclei (Lenton and Vaughan [2009]). In (MacMartin et al. [2013]), the impact of uncertainty in the imposed radiative forcing and the consequent temperature response is compensated through the use of feedback of the observed global-mean surface temperature.

Comprehensive atmosphere-ocean general circulation models (AOGCMs) simulate the combined thermal response of the atmosphere, ocean, land surface and cryosphere to net radiative forcing, the imbalance between planetary energy absorbed from sunlight and the energy emitted to space as 
thermal radiation. While AOGCMs represent state-of-theart in climate modeling, their high spatio-temporal resolution makes them computationally intensive, and quite unsuitable for many applications. For example, the CSIRO Mk3L model takes on the order of 6 weeks on a typical desktop PC to simulate 1000 years of climatic response (Phipps et al. [2011]).

A range of "impulse response function" (IRF) climate models have been proposed in the literature. Nevertheless, shortcomings in these models limit their suitability for the long-term mitigation and geoengineering applications envisaged in this paper, including: identification and validation on very short $(\approx 100$-year) data records (Caldeira and Myrhvold [2013], Good et al. [2013], Geoffroy et al. [2013]), highly simplified underlying climate models (Jarvis et al. [2009], and model validation under limited conditions (Geoffroy et al. [2013], Li and Jarvis [2009]).

In this paper, we apply system identification techniques to a collection of AOGCMs participating in a multimodel ensemble known as phase 3 of the Coupled Model Intercomparison Project (CMIP3) (Meehl et al. [2007]). The dynamic behaviour of each of the AOGCMs in the CMIP3 ensemble is in turn emulated by the reduced-complexity climate model MAGICC (Model for the Assessment of Greenhouse-gas Induced Climate Change), version 6 .

We identify a total of 12 AOGCMs in the CMIP3 suite for which low-order LTI models are able to very closely emulate surface temperature projections generated by MAGICC under each of the four GHG emission scenarios known as the Representative Concentration Pathways (RCPs) in the Fifth Assessment Report (AR5) of the Intergovernmental Panel on Climate Change (IPCC) (van Vuuren et al. [2011], Meinshausen et al. [2011b]), even when extended to centennial timescales.

There are two motivations for employing MAGICC to identify transfer function models, given that MAGICC itself is already a reduced-complexity climate model designed to emulate AOGCMs. First, while MAGICC is a so-called simple climate model, the MAGICC model is nonetheless nonlinear, high-order $(\approx 100)$ and timevarying (Meinshausen et al. [2011a]), making it quite illsuited for the application of control design methodologies requiring low-order LTI plant models. Second, MAGICC serves as a highly convenient proxy for a large number of AOGCMs developed by independent climate modeling groups. Running such AOGCMs directly is complicated and time-consuming at best, and more often infeasible due to the need for software packages which are prohibitively expensive and/or to which access is restricted.

The paper is organized as follows. In $\S 2$ we provide background on the MAGICC climate model, the CMIP3 climate model intercomparison project and the RCP emission scenarios. In $\S 3$ we detail both the methodology for obtaining input-output datasets from MAGICC and the formulation of the system identification problem. Results are presented in $\S 4$, and conclusions are drawn in $\S 5$. The estimated parameters of transfer function representations of 12 climate models from the CMIP3 multimodel ensemble are presented in Appendix A.

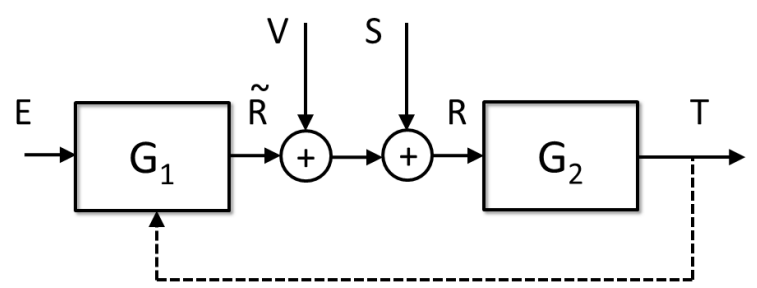

Fig. 1. Block diagram of the MAGICC combined gas cycleclimate model: gas cycle $G_{1}$ and climate model $G_{2}$, emissions $E$, net anthropogenic radiative forcing $\widetilde{R}$, volcanic forcing $V$, solar forcing $S$, net forcing $R$, and temperature anomaly $T$. Dotted line shows climate feedbacks on the carbon cycle

\section{BACKGROUND}

\subsection{The MAGICC climate model}

The model employed in this paper for climate simulations, known as MAGICC, quantifies the movement of energy through the atmosphere, land and ocean due to changes in atmospheric GHG concentrations and radiative forcing. MAGICC has been developed over a period of 20 years (Wigley and Raper [1992], Meinshausen et al. [2011a]), has been used in several IPCC assessment reports (including the most recent draft Fifth Assessment Report (AR5) report) to produce projections of future global mean temperature, and is freely available for download from www.magicc.org

A high-level view of MAGICC is shown in Fig. 1, in which the two major modules are a gas cycle model $G_{1}$ driven by $\mathrm{GHG}$ emissions $E$, and a reduced-complexity climate model $G_{2}$ whose output is the global-mean surface temperature anomaly $T$, measured relative to the year 1765 .

The gas cycle model $G_{1}$ in MAGICC requires as input the annual global anthropogenic emissions of $\mathrm{CO}_{2}$ and other GHGs arising from fossil fuel emissions, other industrial sources and land-use changes, along with emissions of aerosols and tropospheric ozone precursors. Using these emissions, together with modeled fluxes between carbon pools in terrestrial and ocean carbon cycles, the MAGICC gas cycle model determines the atmospheric concentration of GHGs and other radiatively active species, from which the net anthropogenic radiative forcing at the tropopause, denoted $\widetilde{R}\left(\mathrm{~W} / \mathrm{m}^{2}\right)$ in Fig. 1, can be calculated. Together with the influence of volcanic aerosols $V$ and solar activity $S$, the net radiative forcing applied to the climate system $G_{2}$ is given by $R=\widetilde{R}+S+V$.

The climate model $G_{2}$ in MAGICC employs four boxes to represent the thermal properties of the atmosphere (at hemispherical resolution, over both land and ocean), and an upwelling-diffusion-entrainment model of the ocean.

MAGICC is referred to as a reduced-complexity model in recognition of the fact that the representation of the climate system in MAGICC is a highly parameterized simplification of sophisticated AOGCMs which capture climatic response to radiative forcing at significantly higher spatial and temporal resolution. By calibration of 82 pa- 
rameters, MAGICC is capable of emulating the behaviour of each of these far more complex gas cycle-climate models (Meinshausen et al. [2009]).

\section{2 $C M I P 3$}

The World Climate Research Programme's (WCRP's) Coupled Model Intercomparison Project phase 3 (CMIP3) multimodel dataset contains simulation data submitted from 14 climate modeling groups for 23 AOGCMs (Meehl et al. [2007], Annan and Hargreaves [2011]).

Compiled in preparation for the IPCC Fourth Assessment Report (AR4) released in 2007, the CMIP3 multimodel ensemble has been extensively used for climate research. As a multimodel ensemble capturing the results of a range of climate models with differing structural and parametric uncertainties, the CMIP3 ensemble represents a broad range of plausible climate responses.

Of the 23 AOGCMs participating in CMIP3, a total of 19 models contained sufficient data to enable calibration of MAGICC6 to emulate their behaviour; see [Meinshausen et al., 2011a, Section 4]. These 19 AOGCMs are listed in Table 1.

\subsection{Representative Concentration Pathways (RCPs)}

The Representative Concentration Pathways (RCPs) are a set of four time-dependent GHG concentration trajectories developed in preparation for the IPCC AR5. The four $\mathrm{RCPs}$ are named RCP2.6, RCP4.5, RCP6 and RCP8.5 in reference to their associated radiative forcing values in the year 2100 , namely $+2.6,+4.5,+6$ and $+8.5 \mathrm{~W} / \mathrm{m}^{2}$, respectively. RCP2.6 is also referred to as RCP3PD, for Peak-Decline, since the forcing under this trajectory first reaches a peak forcing level of $\sim 3 \mathrm{~W} / \mathrm{m}^{2}$ mid-century before declining to $+2.6 \mathrm{~W} / \mathrm{m}^{2}$ in 2100 .

The RCP3PD pathway represents a strong mitigation scenario, while RCP8.5 is characterized by increasing GHG concentrations over time. The RCP4.5 and RCP6 pathways lie between these two extremes.

In this paper we utilize not the RCP concentrations themselves, but rather the GHG emissions corresponding to these concentrations, as detailed by Meinshausen et al. [2011b].

\section{METHODS}

\subsection{Obtaining input-output data}

Consider the setup in Fig. 1, in which emissions $E$ of well-mixed greenhouse gases and other radiatively active species lead to net anthropogenic radiative forcing $\widetilde{R}$. The climatic response to $\widetilde{R}$ together with additive forcing from the effects of volcanic aerosols $V$ and solar forcing $S$, is represented by the global-mean surface temperature anomaly $T$, relative to the base year 1765 .

The dotted line in Fig. 1 represents climate-carbon cycle feedbacks, wherein the dynamics of the global carbon cycle are influenced by temperature changes, e.g. the rate of uptake of carbon by the terrestrial biosphere and ocean are both temperature-dependent. All values $E, \widetilde{R}, V, S$, $R$ and $T$ are measured annually, and represent global averages. Radiative forcing values are in units of watts per square metre $\left(\mathrm{W} / \mathrm{m}^{2}\right)$; emissions are GHG-specific, and temperature anomaly $T$ is in degrees Celsius.

In this paper, we model the climate response represented by the system $G_{2}$ in Fig. 1, with radiative forcing input $R$ and output temperature anomaly $T$. Obtaining suitable input-output data from MAGICC therefore requires care, since MAGICC is conventionally used as an emissionsdriven emulator. User-specified emissions of GHGs therefore lead to time-dependent atmospheric concentrations and thence to net anthropogenic radiative forcing $\widetilde{R}$. This consequently limits the flexibility over which $\widetilde{R}$ can be used to generate input (excitation) signals to the climate system $G_{2}$.

In this paper a solar radiative forcing signal is superimposed for the purposes of system identification. Since $S$ is additive with anthropogenic radiative forcing $\widetilde{R}$ and can be specified independently of GHG emissions, the input signal can be designed flexibly; we choose a $1 \mathrm{~W} / \mathrm{m}^{2}$ impulse as the superimposed solar radiative forcing signal. Carbon cycle-temperature feedbacks (dotted line in Fig. 1) are turned off during identification experiments to avoid the risk of biased estimates of the model $G_{2}$ due to the feedback loop from $T$ back to model $G_{1}$.

Let $T=\left[T_{1}, T_{2}, \ldots, T_{N}\right]$ be the annual baseline globalmean surface temperature anomalies arising from an $N$ year MAGICC simulation run in response to a userspecified emissions scenario $E=\left[E_{1}, E_{2}, \ldots, E_{N}\right]$, where $E_{t} \in \mathbf{R}^{F}$ and $F$ is the number of distinct GHG forcing agents, and with solar forcing $S=\left[S_{1}, S_{2}, \ldots, S_{N}\right]$. Now let $\widetilde{T}=\left[\widetilde{T}_{1}, \widetilde{T}_{2}, \ldots, \widetilde{T}_{N}\right]$ be the temperature profile in response to perturbed solar forcing $\widetilde{S}=\left[S_{1}+\right.$ $\left.s_{1}, S_{2}+s_{2}, \ldots, S_{N}+s_{N}\right]$, i.e. superimposed solar forcing of $\left[s_{1}, s_{2}, \ldots, s_{N}\right]$, with the same underlying emissions scenario $E$. With these definitions in place, the length$N$ input and output signal records to be used for system identification of $G_{2}$ are given by $u:=\left[s_{1}, s_{2}, \ldots, s_{N}\right]$ and $y:=\left[\widetilde{T}_{1}-T_{1}, \widetilde{T}_{2}-T_{2}, \ldots, \widetilde{T}_{N}-T_{N}\right]$, respectively.

MAGICC simulations commence in 1765 , broadly corresponding to the beginning of the industrial era, and the MAGICC package cannot reliably simulate much beyond year 2500. Moreover, to ensure reliable emulation of climatic response from MAGICC, historical emissions over 1765-2000 are preferred over user-specified emissions injected for the purposes of system identification. Data records available for system identification of $G_{2}$ are consequently limited to less than 750 annually sampled points over 1765-2500. This paucity of data is especially pronounced given timescales in AOGCMs, which are a priori known to be in the range 100-400 years (Olivié et al. [2012]).

\subsection{System identification}

We adopt a model-based framework wherein it is assumed that scalar observations $y_{t} \in \mathbf{R}$ are related to a scalar observed input (excitation) $u_{t} \in \mathbf{R}$ via a transfer function description ( $q$ denotes the forward shift operator): 


$$
y_{t}=G(q, \theta) u_{t}+H(q, \theta) e_{t},
$$

where $e_{t}$ is an independent and identically distributed (i.i.d.) zero-mean noise sequence with variance $\mathbf{E}\left\{e_{t}^{2}\right\}=$ $\sigma^{2}<\infty$, and both $G(q, \theta)$ and $H(q, \theta)$ are scalar rational transfer functions:

$$
G(q, \theta)=q^{-k} \frac{B(q, \theta)}{A(q, \theta)}, \quad H(q, \theta)=\frac{C(q, \theta)}{D(q, \theta)},
$$

where

$$
\begin{aligned}
& A(q, \theta)=1+a_{1} q^{-1}+a_{2} q^{-2}+\cdots+a_{m_{a}} q^{-m_{a}}, \\
& B(q, \theta)=b_{0}+b_{1} q^{-1}+b_{2} q^{-2}+\cdots+b_{m_{b}} q^{-m_{b}}, \\
& C(q, \theta)=1+c_{1} q^{-1}+c_{2} q^{-2}+\cdots+c_{m_{c}} q^{-m_{c}}, \\
& D(q, \theta)=1+d_{1} q^{-1}+d_{2} q^{-2}+\cdots+d_{m_{d}} q^{-m_{d}},
\end{aligned}
$$

for $k$ an integer-valued delay acting on the input, and where $\theta \in \mathbf{R}^{n}$ is a vector specifying the model parameters $a_{i}, b_{i}, c_{i}, d_{i}$.

The mean-square optimal one-step ahead predictor $\widehat{y}_{t}(\theta)$ based on the model structure in (1) is (Ljung [1999]):

$$
\widehat{y_{t}}=H^{-1}(q, \theta) G(q, \theta) u_{t}+\left[1-H^{-1}(q, \theta)\right] y_{t},
$$

with associated prediction error

$$
\varepsilon_{t}(\theta)=y_{t}-\widehat{y}_{t}(\theta)=H^{-1}(q, \theta)\left[y_{t}-G(q, \theta) u_{t}\right] .
$$

Assuming that $N$ samples of $u_{t}$ and $y_{t}$ are available, a quadratic estimation criterion may be defined as

$$
V_{N}(\theta)=\frac{1}{2 N} \sum_{t=1}^{N}\left\|\varepsilon_{t}(\theta)\right\|^{2},
$$

and then used to construct the prediction error estimate $\widehat{\theta}_{N}$ of $\theta$ as

$$
\widehat{\theta}_{N}=\underset{\theta \in \mathbf{R}^{n}}{\operatorname{argmin}} V_{N}(\theta)
$$

The estimate $\widehat{\theta}_{N}$ in equation (6) is computed via a standard Gauss-Newton based search involving iterations $\left\{\theta_{k}\right\}$ starting from an initial guess $\theta_{0}$ which is refined according to

$$
\theta_{k+1}=\theta_{k}+\mu p
$$

where $\mu \in(0,1]$ is a scalar step length, and the search direction $p$ is the solution of

$$
V_{N}^{\prime \prime}\left(\theta_{k}\right) p=V_{N}^{\prime}\left(\theta_{k}\right)
$$

where $\cdot^{\prime}$ denotes differentiation with respect to $\theta$.

In this paper the system $G(q, \theta)$ to be identified is climate model $G_{2}$ in Fig. 1. Attention is restricted to the output error $(\mathrm{OE})$ model structure, in which $m_{c}=m_{d}=0$, so that $C(q, \theta)=D(q, \theta)=1$. We also restrict attention to the case where $m_{a}=m_{b}=: n$, and delay $k=0$. The vector of parameters to be estimated is therefore

$$
\theta=\left[a_{1}, a_{2}, \ldots, a_{n}, b_{0}, b_{1}, \ldots, b_{n}\right] .
$$

In the following section, the UNIT system identification toolbox (Ninness et al. [2013]) is used to identify $\theta$ according to the methodology described above. Custom MATLAB code was written to facilitate the ready exchange of data between MAGICC6, and the MATLAB-based UNIT system identification toolbox.

\section{RESULTS}

\subsection{Setup}

System identification experiments were conducted using MAGICC6 according to the procedure described in $\S 3$, using RCP4.5 as the baseline emissions scenario. Simulation experiments commenced in 1765 and terminated in 2500, implying input-output data series of length $N=736$.

The length- $N$ additive solar radiative forcing perturbation was chosen as a $1 \mathrm{~W} / \mathrm{m}^{2}$ impulse applied in the second year: $[0,1,0, \ldots, 0]$. Climate-carbon cycle feedbacks were turned off during the identification experiments (baseline, and baseline plus solar perturbation), and efficacy of solar forcing set to 1 during all simulations (Meinshausen et al. [2011a], §A4.4).

\subsection{Model validation}

Table 1 lists a total of 20 AOGCMs, corresponding to 19 AOGCMs in the CMIP3 ensemble, together with the MAGICC6 default climate model. For each of these 20 AOGCMs, identification of a linear climate model of order $n=2,3,4$ was performed using the procedure described in $\S 3$.

Each identified model was validated by comparing the MAGICC6 temperature projection of the corresponding CMIP3 model against the output of the identified model, when both MAGICC6 and the linear model are driven by the radiative forcing arising from the RCP8.5 emissions scenario with the carbon cycle feedback in MAGICC6 turned on. Data for order $n=\infty$ in Table 1 corresponds to using the measured impulse response to generate the model output directly via discrete-time convolution with the net radiative forcing input $R$, and therefore represents the best achievable performance obtainable by any LTI model under the prescribed experimental conditions.

Fig. 2 shows the results of a sample validation, in which temperature projections of the MAGICC6 default climate model under RCP8.5 emissions are compared with the output of estimated linear models of order $n=2,3,4, \infty$. While the order $n=2$ model clearly fails to accurately replicate the MAGICC6 projection, the order $n=3$ model does substantially better. Increasing $n$ to 4 or even $\infty$ results in only marginal improvement.

Fig. 3 compares the output of the MAGICC6 default model with the estimated model of order $n=4$ under each of the four RCP emissions scenarios. The model fit is excellent for the RCP3PD, RCP4.5 and RCP6 scenarios, and exhibits only a small residual error under RCP8.5.

Table 1 summarizes the validation results when estimated models are compared with the corresponding MAGICC6 model under RCP8.5, typically the most challenging emissions scenario, as per Fig. 3. Two numbers are presented in each cell of Table 1, where each cell corresponds to a combination of a CMIP3 climate model, and an estimated linear model of order $n$. The upper number in each cell is the root-mean square (RMS) prediction error: $\left(\frac{1}{N} \sum_{t=1765}^{2500}\left(y_{t}-\widehat{y}_{t}(\theta)\right)^{2}\right)^{1 / 2}$, while the lower number is the worst-case prediction error, namely $\max _{t \in\{1765, \ldots, 2500\}}\left|y_{t}-\widehat{y}_{t}(\theta)\right|$. 


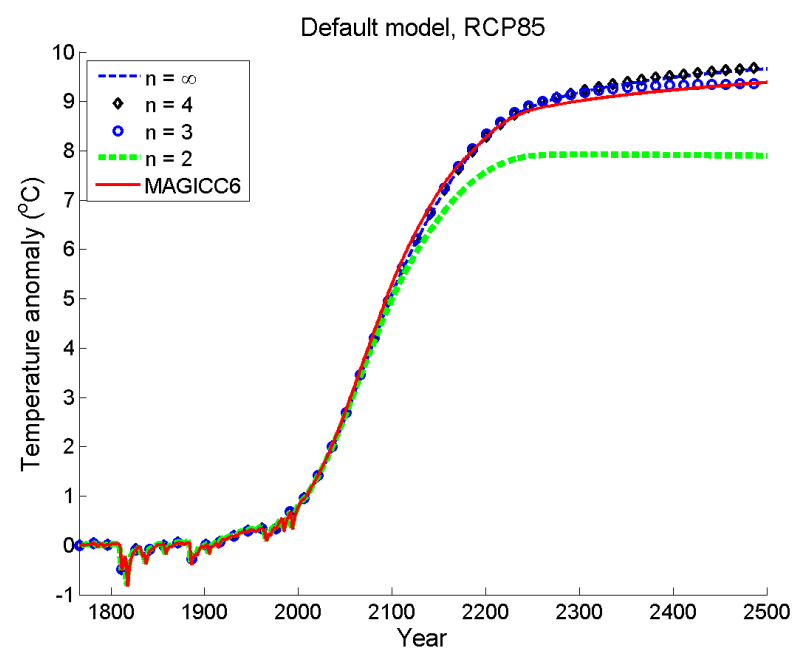

Fig. 2. Temperature projections under the RCP8.5 emissions scenario, using the MAGICC6 default climate model, and estimated linear models of order $n=$ $2,3,4, \infty$.

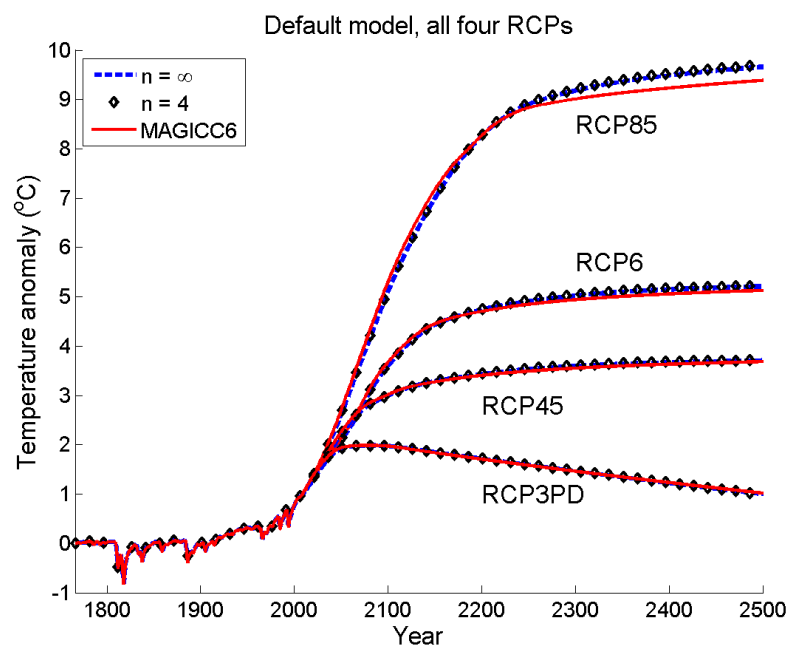

Fig. 3. Temperature projections under the RCP3PD, RCP4.5, RCP6 and RCP8.5 emissions scenarios, using the MAGICC6 default climate model, and estimated linear models of order $n=4, \infty$.

AOGCMs whose names are set in italics in Table 1 exhibit poor model fits regardless of model order $n$. While we conjecture this is due to strong climate-state dependent feedbacks within the climate models themselves (Meinshausen et al. [2011a], $\S \mathrm{A} 4.3)$, further research is needed to pinpoint the precise reason(s).

\subsection{Model parameters}

The estimated linear model parameters for the MAGICC6 default climate model are shown in Table 2, for orders $n=3,4$. A more comprehensive coverage of the CMIP3 multimodel ensemble is presented in Appendix A, where the parameters of estimated linear climate models for the CMIP3 AOGCMs marked with identification (ID) numbers 1-12 in Table 1 are presented following the format in Table 2, for model orders $n=3,4$.

\begin{tabular}{|c|c|c|c|c|c|}
\hline \multirow[b]{2}{*}{ Model name (CMIP3) } & \multirow[b]{2}{*}{ ID } & \multicolumn{4}{|c|}{ Model order $n$} \\
\hline & & 2 & 3 & 4 & $\infty$ \\
\hline \multirow[t]{2}{*}{ ССSМЗ } & & 2.39 & 1.97 & 1.87 & 1.88 \\
\hline & & 3.84 & 3.17 & 2.85 & \\
\hline \multirow{2}{*}{ CGCM3.1(T47) } & 1 & 0.73 & 0.16 & 0.18 & 0.16 \\
\hline & & 1.48 & 0.50 & 0.50 & 0.28 \\
\hline \multirow[t]{2}{*}{ CNRM-CM3 } & 2 & 0.60 & 0.15 & 0.17 & \\
\hline & & 1.23 & 0.50 & 0.50 & 0.34 \\
\hline \multirow[t]{2}{*}{ CSIRO-Mk3.0 } & 3 & 0.60 & 0.20 & 0.23 & \\
\hline & & 1.00 & 0.60 & 0.60 & 0.63 \\
\hline \multirow{2}{*}{\multicolumn{2}{|c|}{ ECHAM5/MPI-OM }} & 7.88 & 7.19 & 7.10 & 7.11 \\
\hline & & 12.4 & 11.3 & 11.0 & 11.0 \\
\hline \multirow[t]{2}{*}{ ECHO-G } & 4 & 0.49 & 0.13 & 0.16 & 0.15 \\
\hline & & 0.98 & 0.47 & 0.47 & 0.28 \\
\hline \multirow{2}{*}{$F G O A L S-g 1.0$} & & 3.70 & 3.24 & 3.14 & 3.15 \\
\hline & & 5.79 & 5.06 & 4.74 & 4.76 \\
\hline \multirow[t]{2}{*}{ GFDL-CM2.0 } & & 2.44 & 1.94 & 1.84 & \\
\hline & & 4.13 & 3.28 & 2.98 & 2.99 \\
\hline \multirow[t]{2}{*}{ GFDL-CM2.1 } & & 2.10 & 1.61 & 1.56 & \\
\hline & & 3.31 & 2.46 & 2.20 & \\
\hline \multirow[t]{2}{*}{ GISS-EH } & 5 & 0.42 & 0.19 & 0.21 & \\
\hline & & 0.71 & 0.46 & 0.46 & 0.50 \\
\hline \multirow[t]{2}{*}{ GISS-ER } & & 2.76 & 2.32 & 2.25 & 2.26 \\
\hline & & 4.79 & 4.04 & 3.76 & 3.78 \\
\hline \multirow{2}{*}{ INM-CM3.0 } & 6 & 0.55 & 0.09 & 0.16 & 0.15 \\
\hline & & 1.00 & 0.41 & 0.41 & 0.25 \\
\hline \multirow{2}{*}{ IPSL-CM4 } & 7 & 0.98 & 0.08 & 0.10 & \\
\hline & & 2.18 & 0.48 & 0.49 & 0. \\
\hline \multirow[t]{2}{*}{ MIROC3.2(H) } & 8 & 1.69 & 0.35 & 0.37 & 0.3 \\
\hline & & 2.37 & 0.98 & 1.04 & 1. \\
\hline \multirow[t]{2}{*}{ MIROC3.2(M) } & 9 & 1.30 & 0.49 & 0.52 & 0.53 \\
\hline & & 2.37 & 0.98 & 1.04 & 1. \\
\hline \multirow[t]{2}{*}{ MRI-CGCM2.3.2 } & 10 & 0.61 & 0.11 & 0.20 & 0.19 \\
\hline & & 1.09 & 0.40 & 0.40 & 0. \\
\hline \multirow[t]{2}{*}{$\mathrm{PCM}$} & 11 & 0.34 & 0.06 & 0.08 & 0.06 \\
\hline & & 0.65 & 0.42 & 0.42 & 0. \\
\hline \multirow[t]{2}{*}{ UKMO-HadCM3 } & 12 & 0.92 & 0.14 & 0.16 & 0.13 \\
\hline & & 1.79 & 0.42 & 0.42 & 0. \\
\hline \multirow[t]{2}{*}{ UKMO-HadGEM1 } & & 2.47 & 1.83 & 1.79 & 1.8 \\
\hline & & 4.29 & 3.16 & 2.94 & 2. \\
\hline \multirow[t]{2}{*}{ Default } & 13 & 0.79 & 0.09 & 0.17 & 0.15 \\
\hline & & 1.486 & 0.37 & 0.39 & 0. \\
\hline
\end{tabular}

Table 1. Validation results for 20 estimated climate models (order $n=2,3,4, \infty$ ) against MAGICC6 emulation of the corresponding model. Radiative forcing input to estimated models is from MAGICC6 simulation run driven by RCP8.5 emissions. Each cell contains RMS error (top) and worst-case error (bottom) over 1765-2500. Estimated parameters for models with an identification (ID) number are presented in Table 2 (model 13, default) and Appendix A (models 1-12) 


\begin{tabular}{lr|rr||cr|cr}
\multicolumn{4}{c||}{$n=4$} & \multicolumn{4}{c}{$n=3$} \\
\hline$b_{4}$ & -0.01537259 & $a_{4}$ & 0.16417502 \\
$b_{3}$ & -0.01948524 & $a_{3}$ & -1.26896279 \\
$b_{2}$ & 0.22347806 & $a_{2}$ & 3.03391175 & $b_{3}$ & 0.01534760 & $a_{3}$ & -0.28985763 \\
$b_{2}$ & 0.06668731 & $a_{2}$ & 1.47594899 \\
$b_{1}$ & -0.33316479 & $a_{1}$ & -2.92905991 & & -0.22572618 & $a_{1}$ & -2.18481788 \\
$b_{0}$ & 0.14459237 & & 0.14459237 & & \\
$b_{0}$ & & & &
\end{tabular}

Table 2. Estimated parameters of MAGICC6 default climate model, with model order $n=$ 3,4 . Coefficients $a_{i}, b_{i}$ are from the model (2)-(3), with $m_{a}=m_{b}=n$

\section{CONCLUSIONS}

The results in this paper establish that the majority of climate models in the CMIP3 multimodel ensemble are very accurately represented using low-order LTI models. The models presented in Table 2 and Appendix A have been shown to have high accuracy when validated against MAGICC6 over centennial timescales and a wide range of GHG emission scenarios (RCP3PD through RCP8.5). It is therefore anticipated that the models in the present paper will serve as a valuable resource for researchers seeking to employ feedback control-based approaches to mitigation and/or climate engineering such as those presented in (Jarvis et al. [2012]) and (MacMartin et al. [2013]), for which low-order LTI models are highly desirable.

While the focus of the present paper is the identification of input-output climate models, it is natural to speculate on the underlying physical interpretation of the models so obtained. A key result in this direction is reported by Levitus et al. [2012], in which it is established that the world ocean accounts for approximately $93 \%$ of the warming of the earth system that has occurred since 1955.

Physical models capturing the response of global mean surface temperature to net anthropogenic radiative forcing would therefore be expected to reflect the primal importance of the ocean as a thermal reservoir. As one example, Geoffroy et al. [2013] develop a simple energy balance model in which the climate system is split into two thermal reservoirs, one capturing the rapid warming of the atmosphere, land and the upper-ocean, and a second reservoir representing the much slower uptake of heat by the deep-ocean. Future research will consider more general control-relevant model structures for global climate, and in particular the use of semi-infinite and box-diffusion climate models (MacMartin et al. [2013], Caldeira and Myrhvold [2013]) in which the modeling of the ocean as a diffusive vertical column leads to fractional-order transfer functions.

\section{REFERENCES}

J. D. Annan and J. C. Hargreaves. Understanding the CMIP3 multimodel ensemble. J. Climate, 24(16):4529 4538, August 2011.

K. Caldeira and N. P. Myrhvold. Projections of the pace of warming following an abrupt increase in atmospheric carbon dioxide concentration. Environ. Res. Lett., 8(3): 034039, 2013.

O. D. Geoffroy, D. Saint-Martin, D. J. L. Olivié, A. Voldoire, G. Bellon, and S. Tytéca. Transient climate response in a two-layer energy-balance model. Part I: Analytical solution and parameter calibration using
CMIP5 AOGCM experiments. J. Climate, 26(6):18411857, March 2013.

P. Good, M. G. Jonathan, J. A. Lowe, and T. Andrews. Abrupt $\mathrm{CO}_{2}$ experiments as tools for predicting and understanding CMIP5 representative concentration pathway projections. Clim. Dyn., 40(3-4):1041-1053, February 2013.

A. Jarvis, D. Leedal, C. J. Taylor, and P. Young. Stabilizing global mean surface temperature: A feedback control perspective. Environ. Modell. Softw., 24(5):665674, May 2009.

A. J. Jarvis, P. C. Young, D. T. Leedal, and A. Chotai. A robust sequential $\mathrm{CO}_{2}$ emissions strategy based on optimal control of atmospheric $\mathrm{CO}_{2}$ concentrations. Climatic Change, 86(3-4):357-373, February 2008.

A. J. Jarvis, D. T. Leedal, and C. N. Hewitt. Climatesociety feedbacks and the avoidance of dangerous climate change. Nature Clim. Change, 2:668-671, July 2012.

T. M. Lenton and N. E. Vaughan. The radiative forcing potential of different climate geoengineering options. Atmos. Chem. Phys., 9:5539-5561, 2009.

S. Levitus, J. I. Antonov, T. P. Boyer, O. K. Baranova, H. E. Garcia, R. A. Locarnini, A. V. Mishonov, J. R. Reagan, D. Seidov, E. S. Yarosh, and M. W. Zweng. World ocean heat content and thermosteric sea level change (0-2000 m), 1955-2010. Geophys. Res. Lett., 39 (L10603), May 2012.

S. Li and A. J. Jarvis. Long run surface temperature dynamics of an A-OGCM: the HadCM3 $4 \times \mathrm{CO}_{2}$ forcing experiment revisited. Clim. Dyn., 33:817-825, May 2009.

L. Ljung. System Identification: Theory for the User. Prentice-Hall, Inc., New Jersey, 2nd edition, 1999.

D. G. MacMartin, B. Kravitz, D. W. Keith, and A. Jarvis. Dynamics of the coupled human-climate system resulting from closed-loop control of solar geoengineering. Clim. Dyn., June 2013.

G. A. Meehl, C. Covey, T. Delworth, M. Latif, B. McAvaney, J. F. B. Mitchell, R. J. Stouffer, and K. E. Taylor. The WCRP CMIP3 multimodel dataset. Bull. Amer. Meteor. Soc., 88(9):1383-1394, September 2007.

M. Meinshausen, N. Meinshausen, W. Hare, S. C. B. Raper, K. Frieler, R. Knutti, D. J. Frame, and M. R. Allen. Greenhouse-gas emission targets for limiting global warming to $2{ }^{\circ} \mathrm{C}$. Nature, 458(7242):1158-1162, 30 April 2009.

M. Meinshausen, S. C. B. Raper, and T. M. L. Wigley. Emulating coupled atmosphere-ocean and carbon cycle models with a simpler model, MAGICC6 Part 1: Model description and calibration. Atmos. Chem. Phys., 11: 1417-1456, 2011a.

M. Meinshausen, S. J. Smith, K. Calvin, J. S. Daniel, M. L. T. Kainuma, J.-F. Lamarque, K. Matsumoto, S. A. Montzka, S. C. B. Raper, K. Riahi, A. Thomson, G. J. M. Velders, and D. P. P. van Vuuren. The $\mathrm{RCP}$ greenhouse gas concentrations and their extensions from 1765 to 2300. Climatic Change, 109(1-2):213-241, 2011b.

B. Ninness, A. Wills, and A. Mills. UNIT: A freely available system identification toolbox. Control Eng. Pract., 21(5):631-644, May 2013. 
D. J. L. Olivié, G. P. Peters, and D. Saint-Martin. Atmosphere response time scales estimated from AOGCM experiments. J. Climate, 25(22):7956-7972, November 2012.

S. J. Phipps, L. D. Rotstayn, H. B. Gordon, J. L. Roberts, A. C. Hirst, and W. F. Budd. The CSIRO Mk3L climate system model version 1.0-Part 1: Description and evaluation. Geosci. Model Dev., 4(2):483-509, 2011.

D. P. van Vuuren, J. Edmonds, M. Kainuma, K. Riahi, A. Thomson, K. Hibbard, G. C. Hurtt, T. Kram, V. Krey, J.-F. Lamarque, T. Masui, M. Meinshausen, N. Nakicenovic, S. J. Smith, and S. K. Rose. The representative concentration pathways: an overview. Climatic Change, 109(1-2):5-31, 2011.

T. M. L. Wigley and S. C. B. Raper. Implications for climate and sea level of revised IPCC emissions scenarios. Nature, 357:293-300, May 1992.
Appendix A. ESTIMATED MODEL PARAMETERS FOR SELECTED CMIP3 CLIMATE MODELS

\begin{tabular}{|c|c|c|c|c|}
\hline ID & \multicolumn{2}{|c|}{$n=4$} & \multicolumn{2}{|c|}{$n=3$} \\
\hline 1 & $\begin{array}{r}-0.00780072 \\
-0.09631684 \\
0.41582418 \\
-0.51756821 \\
0.20591106 \\
\end{array}$ & $\begin{array}{r}0.20375718 \\
-1.41499445 \\
3.20899220 \\
-2.99769633\end{array}$ & $\begin{array}{r}0.00370935 \\
0.14517899 \\
-0.35382780 \\
0.20591106\end{array}$ & $\begin{array}{r}-0.30124226 \\
1.50420005 \\
-2.20176025\end{array}$ \\
\hline 2 & $\begin{array}{r}0.01592588 \\
-0.20599448 \\
0.59357524 \\
-0.63768129 \\
0.23421046 \\
\end{array}$ & $\begin{array}{r}0.20386138 \\
-1.42565902 \\
3.23135785 \\
-3.00951497\end{array}$ & $\begin{array}{r}-0.03387374 \\
0.26106108 \\
-0.46076570 \\
0.23421046\end{array}$ & $\begin{array}{r}-0.33553157 \\
1.58971512 \\
-2.25335441\end{array}$ \\
\hline 3 & $\begin{array}{r}-0.00914905 \\
-0.02267960 \\
0.16944878 \\
-0.23757148 \\
0.09997050 \\
\end{array}$ & $\begin{array}{r}0.21258038 \\
-1.45029042 \\
3.25489213 \\
-3.01714959\end{array}$ & $\begin{array}{r}0.00790198 \\
0.05682645 \\
-0.16425962 \\
0.09997050\end{array}$ & $\begin{array}{r}-0.36121999 \\
1.64358820 \\
-2.28156809\end{array}$ \\
\hline 4 & $\begin{array}{r}-0.04241777 \\
0.03468512 \\
0.21047896 \\
-0.35817491 \\
0.15544568 \\
\end{array}$ & $\begin{array}{r}0.28895013 \\
-1.72714979 \\
3.58257221 \\
-3.14434758\end{array}$ & $\begin{array}{r}0.04487183 \\
0.01291055 \\
-0.21203183 \\
0.15544568\end{array}$ & $\begin{array}{r}-0.31420472 \\
1.51997245 \\
-2.20395527\end{array}$ \\
\hline 5 & $\begin{array}{r}0.02734503 \\
-0.23751993 \\
0.60428981 \\
-0.60880153 \\
0.21470817 \\
\end{array}$ & $\begin{array}{r}0.21406417 \\
-1.45950794 \\
3.26898360 \\
-3.02350201\end{array}$ & $\begin{array}{r}-0.05390142 \\
0.29506456 \\
-0.45548735 \\
0.21470817\end{array}$ & $\begin{array}{r}-0.38037532 \\
1.68971595 \\
-2.30863965\end{array}$ \\
\hline 6 & $\begin{array}{r}-0.02545083 \\
0.01019870 \\
0.19677062 \\
-0.32875013 \\
0.14728929 \\
\end{array}$ & $\begin{array}{r}0.17494871 \\
-1.29373276 \\
3.04920279 \\
-2.93032353\end{array}$ & $\begin{array}{r}0.02940834 \\
0.03162233 \\
-0.20698760 \\
0.14728929\end{array}$ & $\begin{array}{r}-0.24148825 \\
1.34699418 \\
-2.10321676\end{array}$ \\
\hline 7 & $\begin{array}{r}0.01066938 \\
-0.17275176 \\
0.52540780 \\
-0.57983924 \\
0.21654100 \\
\end{array}$ & $\begin{array}{r}0.21977902 \\
-1.48793808 \\
3.30988756 \\
-3.04170285\end{array}$ & $\begin{array}{r}-0.03423855 \\
0.25275604 \\
-0.43470044 \\
0.21654100\end{array}$ & $\begin{array}{r}-0.42283438 \\
1.79207265 \\
-2.36888547\end{array}$ \\
\hline 8 & $\begin{array}{r}-0.02820442 \\
0.01118717 \\
0.21703712 \\
-0.36149698 \\
0.16153780 \\
\end{array}$ & $\begin{array}{r}0.22906519 \\
-1.51835846 \\
3.34217721 \\
-3.05284520\end{array}$ & $\begin{array}{r}0.03107884 \\
0.05082674 \\
-0.24270183 \\
0.16153780\end{array}$ & $\begin{array}{r}-0.37773452 \\
1.69244732 \\
-2.31422552\end{array}$ \\
\hline 9 & $\begin{array}{r}-0.01499312 \\
-0.01475243 \\
0.19801802 \\
-0.29664267 \\
0.12840392 \\
\end{array}$ & $\begin{array}{r}0.20899664 \\
-1.44942086 \\
3.26466519 \\
-3.02421031\end{array}$ & $\begin{array}{r}0.01314203 \\
0.06898568 \\
-0.21008688 \\
0.12840392\end{array}$ & $\begin{array}{r}-0.40474516 \\
1.75090996 \\
-2.34574107\end{array}$ \\
\hline 10 & $\begin{array}{r}-0.01827930 \\
-0.00734917 \\
0.20978083 \\
-0.33135413 \\
0.14725787 \\
\end{array}$ & $\begin{array}{r}0.14780051 \\
-1.19783739 \\
2.93845106 \\
-2.88833030\end{array}$ & $\begin{array}{r}0.02020585 \\
0.05238234 \\
-0.21864590 \\
0.14725787\end{array}$ & $\begin{array}{r}-0.25077246 \\
1.37488297 \\
-2.12221640\end{array}$ \\
\hline 11 & $\begin{array}{r}0.01721115 \\
-0.19450789 \\
0.54527531 \\
-0.58031364 \\
0.21236334 \\
\end{array}$ & $\begin{array}{r}0.16496239 \\
-1.27115200 \\
3.03619138 \\
-2.92994393\end{array}$ & $\begin{array}{r}-0.03642790 \\
0.24795693 \\
-0.42325615 \\
0.21236334\end{array}$ & $\begin{array}{r}-0.29599621 \\
1.48732555 \\
-2.18996957\end{array}$ \\
\hline 12 & $\begin{array}{r}-0.02761938 \\
0.02129309 \\
0.17767306 \\
-0.31510298 \\
0.14381019 \\
\end{array}$ & $\begin{array}{r}0.18976996 \\
-1.35885088 \\
3.13736467 \\
-2.96821547\end{array}$ & $\begin{array}{r}0.03225028 \\
0.02567519 \\
-0.20067854 \\
0.14381019\end{array}$ & $\begin{array}{r}-0.28145114 \\
1.45444623 \\
-2.17159758\end{array}$ \\
\hline
\end{tabular}

